\title{
Entrevista com o professor Luiz Fernando Scheibe*
}

GEOSUL - Hoje, 29 de agosto de 2011, estamos reunidos para realizar a entrevista com o professor Luiz Fernando Scheibe, do Departamento de Geociências da UFSC, desde 1966. Agradecemos antecipadamente a sua disponibilidade em conceder esta entrevista e, nos moldes das demais, iniciamos perguntando onde nasceu, sua família, primeiros anos de estudo...

Prof. Scheibe - Eu nasci em Sarandi, no Rio Grande do Sul, situada no planalto e próxima a Passo Fundo, Carazinho. É uma cidade típica de colonização italiana e a minha família era uma das poucas de origem alemã. Meu pai era mecânico de automóveis e principalmente de caminhões e depois foi revendedor Ford lá em Sarandi. Nasci em dia que estava nevando, segundo a minha mãe, mas consegui me criar bem. Fiz o primário no grupo escolar Dr. João Carlos Machado, uma escola pública muito boa. Meu pai era comerciante e minha mãe dona de casa, mas muito ligada na leitura, sempre lendo, muitos livros e principalmente a Seleções, que eu lia também desde criança, aquele ranço horroroso da guerra fria, além de muitas histórias em quadrinhos e etc. Quando tinha 11 anos nasceram as minhas duas irmãs gêmeas e eu passei um ano em Sarandi fazendo o primeiro ano ginasial e cuidando da que não estava doente. No segundo ano fui para o Instituto Educacional, um colégio metodista de Passo Fundo, a $80 \mathrm{~km}$ de Sarandi, onde fiquei interno por seis anos até o final do colegial. Este colégio tinha uma concepção interessante, pois afirmavam a liberdade com

Professor Titular do Departamento de Geociências, do Programa de Pós-Graduação em Geografia e Doutorado Interdisciplinar em Ciências Humanas da UFSC. Participam da entrevista a professora Sandra Maria de Arruda Furtado, o geógrafo Luciano Augusto Henning e Maria Dolores Buss. Texto revisado e autorizado pelo entrevistado (scheibe@cfh.ufsc.br).

Geosul, Florianópolis, v. 25, n. 50, p 239-259, jul./ago. 2010 
Entrevista com o professor Luiz Fernando Scheibe

responsabilidade e não foi um peso para eu ser aluno interno. Ali fiz o científico, pela manhã, e contabilidade, de noite. Fiz a contabilidade por que meu pai queria que eu fosse trabalhar na empresa lá em Sarandi, que precisava de alguém para "assinar a escrita", como se dizia naquela época. Tinha um contador ótimo, meu tio, mas que não tinha o título, e como técnico em contabilidade eu poderia suprir esta deficiência da firma. Tenho um irmão três anos mais velho do que eu, que um dia chegou lá no internato e disse que ia trabalhar com meu pai lá na firma. Isso abriu para mim toda uma nova perspectiva, em que passei a considerar com toda a liberdade o que eu ia fazer da minha vida. Eu tinha um professor de filosofia, o professor Amaral, que me orientou no sentido de pegar uma folha de almaço e em um dos lados escreverem as profissões e no outro, as vantagens e desvantagens de cada uma. De fato eu fiz isto. E na época, 1960, estava começando no Brasil a CAGE, Campanha de Formação de Geólogos, que dava condições especiais para quem fizesse esta carreira (uma delas era a isenção do serviço militar). Era a época do JK e estavam sendo criados no Brasil os primeiros cursos de geologia. Alguns alunos saídos de Passo Fundo faziam propaganda do curso também. E uma das vantagens que eu elenquei na época era que parte da vida profissional era no campo e outra parte no laboratório, o que me atraía como uma forma interessante de vida.

GEOSUL - E onde foi feito o curso?

Prof. Scheibe - Na Escola de Geologia da UFRGS, de 1961 a 1964. Começo em 61, no ano da Legalidade, que foi a briga do Brizola para garantir o Jango na presidência, após a renúncia do Jânio. Aí começam a me pegar mais as questões sociais e políticas, em que até então eu não era muito ligado. Várias coisas favoreceram para isto, uma delas foi ler a Geografia da Fome, que foi para mim uma coisa muito impactante, principalmente pela indignação do Josué de Castro ao mostrar que (já então) havia alimentos para todos, e apesar disto continuava a haver muita fome, no Brasil e no mundo. A partir daí comecei a ter uma visão 
Entrevista com o professor Luiz Fernando Scheibe

social mais clara. Naquela época muitos universitários eram engajados e tinha JEC, JUC, AP (que era o braço político da JUC), e pelo lado das igrejas protestantes havia a União Cristã dos Estudantes do Brasil (patrocinada pelo Conselho Mundial de Igrejas), que era equivalente à JUC. Em Porto Alegre a ACA, Associação Cristã de Acadêmicos, era filiada à UCEB, e orientada por um pastor muito aberto, o Godofredo Boll. Isto tudo era potencializado porque morei na Casa do Estudante Evangélico, uma de duas, mantidas pela comunidade evangélica de Porto Alegre. E todas as tardes, lá pelas 18 horas, a gente se reunia para tomar chimarrão e conversar sobre as notícias do dia, o filme que tinha visto, o último livro lido, etc.

GEOSUL - Então em 64 você estava na universidade?

Prof. Scheibe - Sim. O Curso de Geologia tinha uma inserção política relativamente forte e em dezembro de 1963, o paraninfo convidado pelos formandos foi o Leonel Brizola. No dia seguinte foi manchete no Correio do Povo que o Leonel Brizola tinha feito um "discurso incendiário" na UFRGS. E o orador da turma tinha sido o Reinhardt Fuck, que morava também lá na casa e que hoje é professor emérito da Universidade de Brasília. Até conversamos sobre alguns tópicos do discurso. Em primeiro de abril de 1964, quando houve o golpe militar, o pessoal do DOPS foi direto procurar lá os alunos comunistas da geologia. Interrogaram os professores para dar os nomes, e não houve uma única denúncia. Os livros "subversivos" do Centro Acadêmico foram colocados no forro da sede e somente depois de quatro ou cinco anos é que os eletricistas da universidade acharam as caixas, denunciaram, mas já não houve repercussão. Até o golpe a gente participava muito das lutas nacionalistas: acampamos na Praça da Alfândega em defesa da Petrobrás, éramos favoráveis à Minerobrás, Monopólio Estatal de Exploração de Minérios no Brasil. No final de 1963 os estudantes de geologia foram até a cidade de Rio Grande para "tomar" a Refinaria Ipiranga, que era particular. Tinha o CPC, Centro Popular de Cultura, que encenava peças sobre o 
Entrevista com o professor Luiz Fernando Scheibe

subdesenvolvimento e coisas do gênero, e as músicas incitavam (cantando) "à reforma agrária, e universitária, e jurídica e bancária". Eu nunca cheguei a me filiar a um partido político e a minha participação foi muito através da ACA, da UCEB; isto fez com que eu não fosse considerado radical e ao mesmo tempo não chegasse a conquistar a confiança dos meus colegas mais esquerdistas. Em dezembro de 64 me formei e convidamos o professor Eurico Rômulo Machado, nosso primeiro professor de Geologia Geral, para paraninfo, pois não era mais possível convidar nenhum político. Eu fiz o discurso da turma, falando de Tiradentes, de Joaquim Silvério dos Reis, o delator de Tiradentes, defendendo a Petrobrás, tudo muito por metáforas devido à situação que o Brasil vivia.

GEOSUL - Você se forma em 1964 e vem trabalhar em Santa Catarina no Laboratório de Análises de Solos da Secretaria de Agricultura e acredito que muito do conhecimento da geologia do estado advém deste seu trabalho. Fale um pouco sobre esta fase de sua vida e quando começa a trabalhar na UFSC.

Prof. Scheibe - Antes de me formar, nas férias de verão de 63 para 64, fiz um estágio de dois meses na Petrobrás. E tive muita sorte porque acompanhei o trabalho integral da perfuração de um poço, inclusive com os ensaios finais. Isto foi no interior da Bahia, no município de Catu, perto de Alagoinhas. A gente (o geólogo Fábio Koff Coulon e eu) vivia em um trailer e de duas em duas horas, noite e dia, um de nós examinava e descrevia uma amostra daquilo que estava sendo perfurado. Um tédio. Não tinha nada daquela aura do "geólogo aventureiro". Os únicos momentos melhores eram quando iam trocar as ferramentas de sondagem, o que durava em torno de seis horas, e a gente pegava o jipe, ia para Salvador, tomava um banho, jantava bem e voltava correndo para o poço. Quando me formei, como o meu relatório de estágio tinha sido muito bom (acompanhei o poço inteiro), a Petrobrás me convidou para trabalhar em geologia de sub-superfície da Bahia. E fiquei pensando que era muito tedioso. Ao mesmo tempo os professores 
Entrevista com o professor Luiz Fernando Scheibe

lá da Escola tinham vindo a Santa Catarina para fazer um levantamento preliminar sobre a jazida de fosfato de Anitápolis, da qual o governo do Estado era detentor dos direitos de mineração. Como precisavam de uma avaliação da viabilidade de exploração econômica da jazida, os professores me indicaram para trabalhar no então Laboratório de Química Agrícola e Industrial (LQAI), para esta avaliação. No final do ano de 1964 vim até Santa Catarina para conversar com o Diretor do laboratório, o Engenheiro Químico Aloysio Leon da Luz Silva; naquela época estava em vigência o PLAMEG, Plano de Metas do Governo, que permitia para o governo contratar sem concurso e pagando um pouco mais do que os salários normais do estado. Então não era o salário da Petrobrás, mas também não era tão ruim. E eu preferi trabalhar aqui. Felizmente, o Dr. Aloysio me pediu para convidar outro geólogo para trabalhar comigo: lá no "Chatô" da geologia, em Porto Alegre, encontrei alguns colegas que estavam esperando para ir trabalhar com água subterrânea no Ceará e ainda não tinham sido chamados. Um deles era o Victor Hugo Teixeira, que aceitou vir também para o LQAI, em janeiro de 1965. Começamos imediatamente a trabalhar em Anitápolis, com uma sonda emprestada da CPCAN em Criciúma, um jipe e o laboratório para fazer as análises químicas. Passávamos a semana lá, coletando amostras das rochas com apatita e acompanhando as (lentas) sondagens. Em 1966 já havíamos chegado à conclusão de que havia uma reserva importante, mas diferente de Cajati (que fomos visitar, no então município de Jacupiranga, SP) - onde o minério todo é um carbonatito e o resíduo de separação do fosfato é usado para fazer cimento, sem quase nenhum rejeito: em Anitápolis, tirando a apatita (o fosfato), mais de $90 \%$ é rocha considerada estéril, e naquela época não se sabia o que se fazer com este rejeito. Então concluímos, em nosso relatório, que não seria econômica a exploração, naquele momento. Em 1968, com o novo código de mineração, a CPRM requereu a área e fez uma nova pesquisa, com um grande número de sondagens, e concluiu que a exploração era econômica, vendendo os direitos da área para a Adubos Trevo. Até 
Entrevista com o professor Luiz Fernando Scheibe

hoje não há exploração lá. O EIA-RIMA do novo projeto, apresentado pela Bunge e pela Yara, que é uma firma norueguesa de fertilizantes, sugere que os rejeitos sejam depositados em duas barragens construídas pelos próprios rejeitos ao longo do Rio Pinheiros, e que ao final da exploração teriam, cada uma, 56 metros de altura. Temos contestado a segurança desse projeto, já que a área é uma caldeira vulcânica onde a única saída é a do rio Pinheiros, e que está sujeita a chuvas torrenciais e neste caso, a exemplo de outras por nós estudadas, as barragens não vão ter condições de segurar este rejeito. Meu parecer para o Ministério Público é que esta área deve ser sim explorada, mas deve ser usada integralmente para rochagem, isto é, rocha finamente moída que incorporada ao solo, melhora as suas características químicas ao longo tempo. Então incorporarão ao solo não só o fósforo, mas também o potássio (a rocha tem $4 \%$ de $\mathrm{K}_{2} \mathrm{O}$ ), magnésio e cálcio, além de outros. E naquela região, onde a AGRECO faz agricultura orgânica e pode usar este tipo de material, haveria uma melhora fantástica dos solos. Outros problemas lá são a produção local do ácido sulfúrico que será estocado, e a proveniência da lenha (36 caminhões diários!) para a secagem do superfosfato.

GEOSUL - Mas voltando à pergunta, como você conheceu o restante de Santa Catarina lá no laboratório e a sua entrada para a UFSC.

Prof. Scheibe - Eu e o Victor Hugo éramos os geólogos do governo de Santa Catarina. Qualquer rocha ou mineral que aparecesse no estado e quisessem saber o que era, encaminhavam para o nosso laboratório. $\mathrm{O}$ movimento era tanto que até $\mathrm{o}$ laboratório mudou de nome, passou a chamar-se de Laboratório de Análises de Solos e Minerais (LASM).. E nós nos considerávamos meio como coveiros, pois o pessoal chegava com um mineral bonito e brilhante e nós enterrávamos muitos dos sonhos: não é ouro, é só vermiculita.... O Vitor Hugo trabalhou também com a fluorita no sul de Santa Catarina, fez um fantástico estágio em águas subterrâneas nos Estados Unidos. E como o laboratório estivesse ligado à Secretaria da Agricultura, os corretivos da acidez 
Entrevista com o professor Luiz Fernando Scheibe

dos solos eram muito importantes. Então começamos a fazer análises dos calcários, o que nos levou para a região de Botuverá eVidal Ramos, a Lages, onde havia uma fábrica que usava os dolomitos da Formação Irati, e ao sul do estado onde há várias ocorrências desses dolomitos. Com "nosso" jipe, conhecemos muito do estado (FOTO!). Também teve a fase do Planejamento Integrado das Associações de Municípios (AMURES, AMMVI, AMESC...), e nós éramos contratados pelo escritório que fazia os planejamentos para fazer a parte dos recursos minerais. E a gente percorria um a um dos municípios.

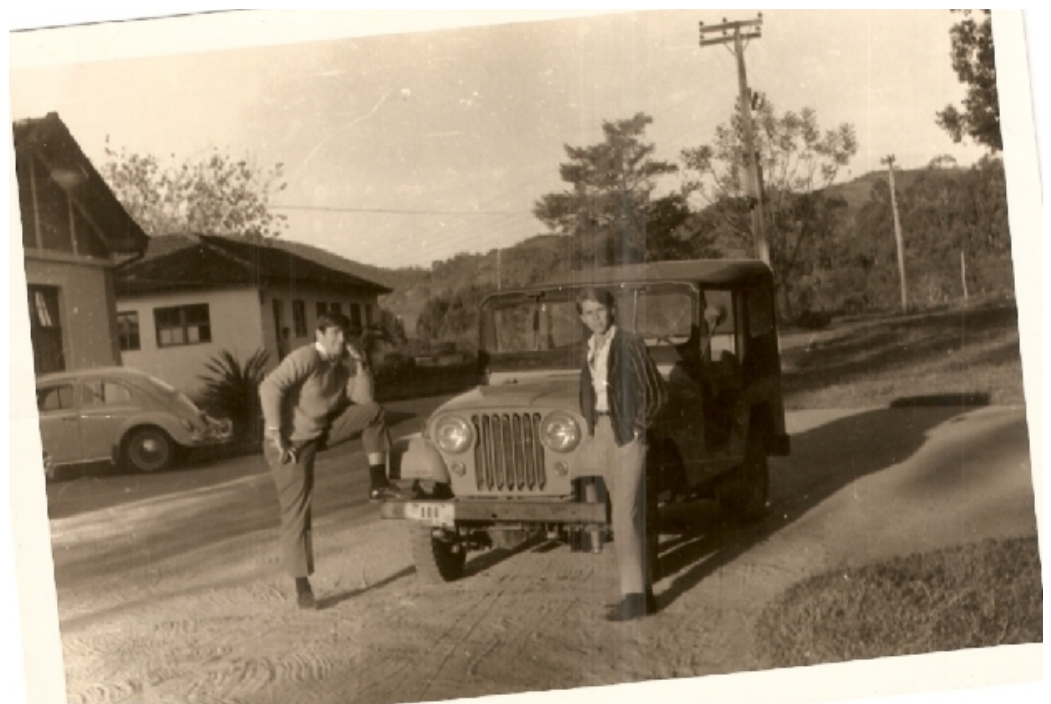

Foto: Nos anos 1960, Scheibe, Victor Hugo e o jeep 184 do LASM na cidade de Brusque.

Em janeiro de 1966 fui convidado pelo Prof. Francisco Kazuihko Takeda para trabalhar no Curso de Geografia da Faculdade de Filosofia, como seu assistente. Fui contratado como Auxiliar de Ensino, por 12 horas semanais. No primeiro semestre eu assistia aulas e ajudava os alunos nas práticas. No ano seguinte ele foi 
Entrevista com o professor Luiz Fernando Scheibe

fazer um curso de Geoprocessamento no INPE e eu fiquei sozinho dando aulas. Em 1968-9, com a reforma do ensino havia muito trabalho. Eu fiquei 11 anos como auxiliar de ensino. Em 1976 fiz concurso para professor assistente em 24 horas semanais, o que representou uma boa melhoria de salário. $\mathrm{Na}$ época o meu salário do estado ia minguando cada vez mais, já sem Plameg, e sempre fui CLT no estado, de forma que crescia a importância da universidade na minha carreira. Quando fui fazer o mestrado em Porto Alegre, em 1976-77, fui com bolsa do PICD.

GEOSUL - Mas você já tinha ido para a Áustria?

Prof. Scheibe - Sim, em 1969-70 passei oito meses na Universidade de Viena e no Serviço Geológico da Áustria, fazendo um curso de especialização da UNESCO em rochas ígneas e metamórficas. E passei a ter uma nova compreensão das rochas e especialmente dos minerais, o que foi muito valioso depois, quando passei a ministrar aulas de Mineralogia para o curso de química. Eu sempre fiquei mais ligado à Geografia e ao Centro de Filosofia e Ciências Humanas, enquanto o Vitor Hugo entrou nas Engenharias, também em 1966, e fez sua carreira por lá.

Tem também outro causo. Em 1967 o governo de Santa Catarina criou uma lei que facilitava a implantação de indústrias, através do redirecionando dos impostos; o desenvolvimento do país era estrondoso, com o consumo de cimento dobrando todo ano. Também havia sido criado o $\mathrm{BNH}$ e não havia cimento que chegasse. O pessoal sabia que havia calcário no vale do rio ItajaíMirim, pois a Votorantin usava calcário lá do Ribeirão do Ouro na sua fábrica de Itajaí. E alguns empresários e políticos de Brusque resolveram montar uma fábrica de cimento. Montaram a sociedade, a Cimenvale, venderam ações pelo estado inteiro e só depois é que foram buscar o calcário. Aí o Victor Hugo e eu fomos designados, pelo diretor do LASM para procurar jazidas de calcário. Aí passamos anos indo para Botuverá, com equipe de topografia, e o seu Érico Barni, que conhecia toda a região, como mateiro. E trabalhei com isto até ir para a Áustria. Quando voltei já tinham 
Entrevista com o professor Luiz Fernando Scheibe

contratado mais dois geólogos. Finalmente encontramos, já perto de Vidal Ramos, duas boas jazidas (nos ribeirões do Tigre e do Cinema) com uma reserva que justificaria a abertura de uma fábrica de cimento, mas já era 1970 e a economia estava começando a declinar. O grupo da Cimenvale não conseguiu instalar sua fábrica, e os direitos das jazidas foram vendidos para a Votorantin. Que também não minera lá. Mas a Cimenvale pagava diárias de campo, o que compensava os salários mais baixos no estado. Depois de 1968, com o novo código de Mineração começou a haver muitas solicitações para pedidos de pesquisa mineral, e alguns relatórios de pesquisa também. Com isto também conhecemos muito da geologia de SC, pois só fazíamos os pedidos após trabalhos de campo. Conhecemos muitas jazidas de argilas, quartzo, sílica e outros materiais para cerâmica, águas minerais, fluorita...

Em 1975 o Governo Konder Reis cria a SETMA, Secretaria de Tecnologia e Meio Ambiente. A principal função da SETMA era viabilizar a Siderúrgica de Santa Catarina, a exemplo do que ocorreu no Rio Grande do Sul com a Aços Finos Piratini. E fui chamado do LASM para assessorar o Secretário, Batista Pereira, um dos grandes mineradores de carvão do sul do estado. Mas na mesma secretaria, contraditoriamente, o Pe. Raulino Reitz tinha outro plano, que era o de criar o Parque Estadual da Serra do Tabuleiro. E eu trabalhava um pouco estudando os carvões, mas principalmente em fotos aéreas, ajudando na delimitação do Parque. Deixei este trabalho de assessoria para fazer o mestrado em geologia em 1976 na UFRGS, e a minha esposa Leda foi também fazer o mestrado em Pedagogia. Passamos dois anos em Porto Alegre. Na volta do mestrado deixei de trabalhar no estado e peguei o regime de 40h, sem DE, na UFSC.

GEOSUL - No seu Mestrado na UFRGS e no doutorado feito na USP, você trabalhou no Domo de Lages. Como se deu este encantamento com Lages?

Prof. Scheibe - Aqui tem que ser feita uma homenagem ao Janjão, o garimpeiro João Lemos da Silva, de Lages. Antes de eu 
Entrevista com o professor Luiz Fernando Scheibe

fazer o mestrado ele aparece lá no LASM pedindo para analisar "este carbonatito". Carbonatitos são rochas carbonáticas ígneas e bastante raras. Olhei a amostra e como já conhecia o carbonatito de Anitápolis, embora muito diferente, pedi uma análise química dele e também fui a Porto Alegre e levei para o meu colega e até agora grande amigo, desde os tempos de escola, Jorge Alberto Villwock, professor de mineralogia na UFRGS. Ele confirmou que de fato devia ser um carbonatito. Fui com o Janjão para Lages e fiz o requerimento de pesquisa para a mesma empresa que explorava os dolomitos do Irati para corretivos de solos. Então quando fui para o mestrado fui estudar esta ocorrência de carbonatito de Lages, que é mais tardio que o de Anitápolis, sem apatita mas muito rico em elementos químicos mais raros, as chamadas terras raras. A ocorrência também não é muito grande, e até hoje não é explorada. A partir disto, me envolvi mais com o Janjão e alguns empresários que queriam explorar as bauxitas de Lages. E fiz muita amostragem em poços de até 20 metros de fundura, e descia pendurado em uma corda, puxada por um sarilho. Mas voltando ao carbonatito, nada dizia que este tipo de rocha rara apareceria lá e a bibliografia na época era escassa. Apresentei trabalhos em congressos e, junto com meu orientador no mestrado, o Prof. Milton Luiz Laquintinie Formoso, publicamos um artigo na Revista Brasileira de Geociências, que até hoje é um marco na utilização petrológica das terras raras no Brasil. Cerca de um ano depois que voltei do mestrado chega de novo o Janjão, agora na UFSC, dizendo: Doutor, analisa este kimberlito. Esta é a rocha portadora dos diamantes, que ocorrem em Kimberley, na África do Sul. Vale dizer que o Janjão trabalhou, desde a infância, com todos os geólogos que passaram por Lages, e que tive o privilégio de aprender com ele, um pouco de seu extraordinário conhecimento de toda a geologia da região. Em 1980 vou para a USP, para trabalhar como tese de doutorado a Geologia e Petrologia do Complexo Alcalino de Lages, tendo como orientador o Prof. Celso de Barros Gomes. Mas continuei estudando os kimberlitos, com auxílio do Janjão, suas peneiras e sua bateia, e o estímulo constante 
Entrevista com o professor Luiz Fernando Scheibe

de nosso místico amigo, Plátano Lenzi: não encontramos diamantes, mas sim safiras, algumas com qualidade gemológica.

GEOSUL - Mas com toda esta formação muito geológica, comente sobre a sua entrada na Geografia, em que você transita muito bem, entre a parte física e a parte humana.

Prof. Scheibe - Na verdade entrei na Universidade no antigo Departamento de Geografia e a minha atividade de professor sempre foi no sentido de ensinar uma geologia que fosse importante para os geógrafos. Em 1962, enquanto era estudante, eu fui professor de geografia em um curso gratuito para adultos, que era oferecido pela Federação dos Estudantes da UFRGS. Em 1966, quando entro na universidade, junto com o professor Takeda, sempre víamos a geologia como parte do curso de geografia. Mesmo nos 10 anos em que estive no LASM, lá foi feito o mapeamento dos solos do estado; a questão dos corretivos de solos e a agricultura eram muito importantes, assim como a água. Embora eu tenha feito uma formação acadêmica muito especializada na Petrologia das Rochas Alcalinas no mestrado e doutorado, o meu dia a dia tanto no laboratório como na universidade era muito mais abrangente, e com visão mais ampla da geologia. Com o Prof. João José Bigarella, que apesar de ser químico é um grande geógrafo, e com diversos outros professores quase completei, ainda nos anos sessenta, um curso de especialização em Geomorfologia Climática, interrompido quando fui para a Áustria. Graças à intervenção do professor Victor Antonio Peluso Junior, fiz em 1984 um estudo comparativo dos mapas geológicos de Santa Catarina que estavam sendo elaborados na época, pelo DNPM e pelo IBGE, e somado ao que eu já conhecia do estado fiz uma sinopse da geologia do estado (publicada em 1986 no número 1 da Geosul, o que muito me orgulha), e que tentava explicar a geologia de Santa Catarina de modo mais acessível. Hoje, precisa ser revisada, mas ainda a indico a todos meus alunos da Geografia. 
Entrevista com o professor Luiz Fernando Scheibe

De fato, quando terminei meu doutorado vi que não havia condição de orientar alunos da Geografia em petrologia de rochas alcalinas, que era a minha grande especialidade. Mas eu ainda continuava trabalhando com isto. Em 1986/1987 veio um grupo de pesquisadores italianos para o Brasil e eu os acompanhei, com o Prof. Celso, a Lages, Jacupiranga, Tunas, e Piratini. Fiz um pós-doutorado com eles na Universidade La Sapienza de Roma em 1987, e estágios em laboratórios de Ferrara, em 1988 e 89. Em 1989, junto com a professora Sandra, após o término do seu doutorado, estudamos os diques de lamprófiros alcalinos do entorno de Anitápolis.

Ao voltar do doutorado assumi, em 1987, a coordenação da PósGraduação em Geografia. Passei a orientar diversos geógrafos, e fui me inteirando da literatura geográfica. Fui, então, agraciado com a organização do II ENESMA, Encontro Nacional de Estudos sobre o Meio Ambiente, que foi trazido para cá pelos professores Bigarella e Carlos Augusto de Figueiredo Monteiro. E para participar chamamos todos os geógrafos brasileiros que trabalhavam com meio ambiente: entre outros, os professores Aziz Ab'Saber, Carlos Walter Porto Gonçalves, Antonio Christofoletti. Este encontro foi um sucesso de público e de mídia, e deu uma marca ambiental ao nosso curso. Na conferência de abertura, o Prof. Carlos Augusto apresentou os primeiros resultados dos seus estudos sobre os fenômenos complexos, maravilhando a todos os presentes. A partir de então, ficou clara a importância de trabalhar com a questão ambiental, e logo criamos, no Departamento de Geociências, o Laboratório de Análise Ambiental - LAAm (www.laam.cfh.ufsc.br). Em 1991 a Eletrosul nos chamou para propor um projeto de delimitação de novas áreas para termelétricas no sul do estado. A associação não prosperou, mas apresentamos ao CNPq o projeto integrado de pesquisa "Qualidade Ambiental da Região Sul Catarinense", base de inúmeros trabalhos de pesquisa efetuados no âmbito do LAAm.

Mais ou menos nessa época assumi a responsabilidade, inicialmente em parceria com a Profa. Maria Dolores Buss, pela disciplina de Análise da Qualidade Ambiental, obrigatória no curso 


\section{Entrevista com o professor Luiz Fernando Scheibe}

de mestrado em Geografia e que fora criada, também, pelo Prof. Carlos Augusto. Por vários anos seguidos organizamos trabalhos de campo em diversos municípios, um pouco ao estilo dos antigos Congressos Brasileiros de Geografia: levávamos outros professores além dos vinte mestrandos, e fazíamos uma verdadeira análise dos aspectos físicos e socioeconômicos do município, resultando preciosos trabalhos de alunos como os que publicamos na Geosul 16 (1993) sobre Lauro Müller, ou no livro, co-organizado pelo Prof. Joel Pellerin, Qualidade Ambiental de Municípios de Santa Catarina: o Município de Sombrio (Ed. FEPEMA, 1997)

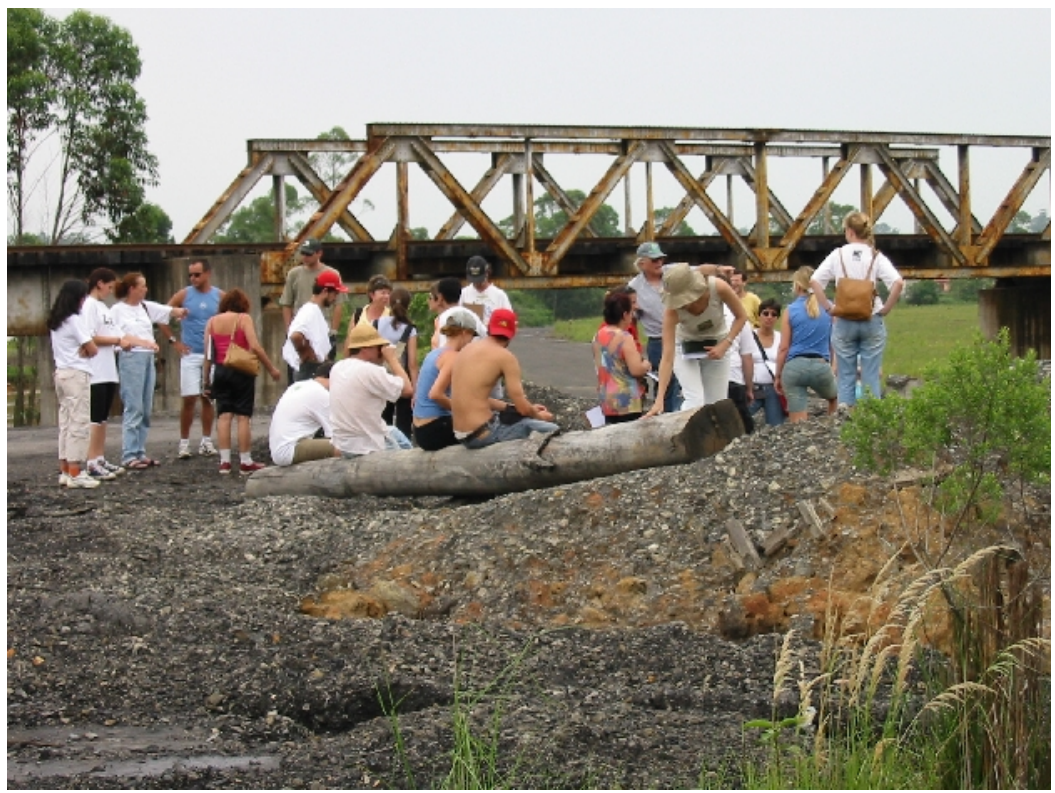

Foto: Junto ao rio Sangão, em Forquilhinha, trabalho de campo de Análise da Qualidade Ambiental, com Dolores, Sandra, Henrique...

GEOSUL - Você também foi um dos primeiros a trabalhar com a interdisciplinaridade. Quando isto inicia e quais as dificuldades encontradas? 
Entrevista com o professor Luiz Fernando Scheibe

Prof. Scheibe - Em 1990, logo depois do II Enesma, ocorre aqui em Santa Catarina o Seminário Nacional Universidade e Meio Ambiente, que tinha um patrocínio federal e era realizado a cada dois anos. Desta época surge uma forte parceria e grande amizade com o professor Carlos Walter Porto Gonçalves. Era muito clara nesses seminários a consciência de que a questão ambiental tem que ser tratada de modo interdisciplinar. Em 1991, quando sou candidato a reitor da UFSC, a nossa campanha foi pautada em uma universidade mais aberta, mais abrangente. E promovemos uma série de conferências (o Ciclo de Conferências Mais Universidade), do Darci Ribeiro, do Antonio Houais, do Maurício Tragtemberg, do geógrafo Orlando Valverde, da Zezé Mota, entre outros. Não fomos para o segundo turno, mas no ano seguinte fui eleito para a direção do $\mathrm{CFH}$. Antes disto a professora Ana Maria Beck já tinha desencadeado junto com outros professores um projeto para a criação de um Doutorado Interdisciplinar no CFH. Após muitas discussões, o programa foi criado, e a primeira área de concentração foi a de Sociedade e Meio Ambiente. Desde então este programa já formou muitos doutores, com teses de muito boa qualidade, premiadas em vários concursos. $\mathrm{Na}$ criação do curso tivemos problemas com a CAPES, que encaminhava o projeto, por que mencionava o meio ambiente, para os biólogos ou ecólogos para dar parecer. Ai se fez modificações no projeto original, ficando Doutorado Interdisciplinar em Ciências Humanas, com três áreas de concentração: Sociedade e Meio Ambiente, Condição Humana na Modernidade e Estudos de Gênero. Depois de ser diretor do $\mathrm{CFH}$, assumi novamente como coordenador da pós-graduação em geografia, durante dois anos. Em todos esses anos, um dos autores que mais me marcou foi o Milton Santos com o livro "A Natureza do Espaço: Técnica e Tempo, Razão e Emoção” (Ed. Hucitec, 1996). Quando fui fazer um estágio com o prof. Gerd Kohlhepp na Universidade de Tübingen, Alemanha, em 1997, comecei a ler este livro numa viagem de trem, de Tübingen para Zurique. Li, reli e o meu exemplar está todo anotado. Aquele para mim é o livro mais importante que o Milton Santos escreveu, e ele mesmo dizia isto, é aquele que dá explicações para todos os fenômenos geográficos e 
Entrevista com o professor Luiz Fernando Scheibe

sociais, para a nossa vida. Eu o tenho usado muito, e numa turma do doutorado em geografia trabalhamos capítulo por capítulo. Propus então aos alunos que escolhessem para seu trabalho final cada uma das tríades de palavras do Milton Santos que alinhei em forma de poesia (que dediquei a ele quando lhe entregamos o título de Doutor Honoris causa da nossa universidade). O resultado foram trabalhos tão interessantes que com eles eu e a então doutoranda Adriana Dorfmann organizamos o livro Ensaios a partir de 'A Natureza do Espaço (Ed. Fundação Boiteux, 2007).

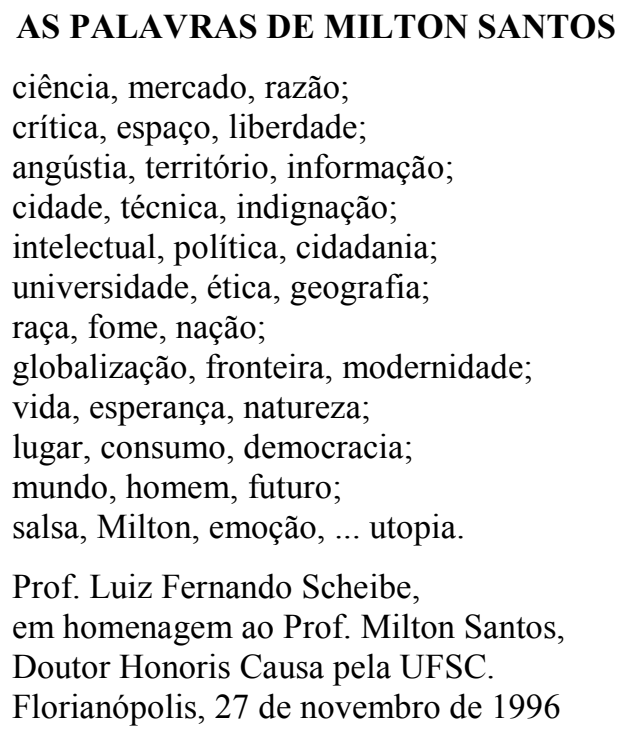

GEOSUL - Scheibe, você teve muitos envolvimentos com trabalhos de extensão universitária, como no maciço do Morro da Cruz, nos desastres naturais do sul do estado, além de dar parecer em grandes projetos, como no caso do projeto da mineração de Anitápolis. Gostaria de perguntar como você vê a participação do professor universitário na extensão? 
Entrevista com o professor Luiz Fernando Scheibe

Prof. Scheibe - De um modo geral quem tem um título de professor universitário é muito considerado pela sociedade. E este fato faz com que as intervenções que se faça são levadas muito a sério e como uma palavra definitiva, embora a gente saiba que são opiniões baseadas em fatos científicos, mas que não são necessariamente certezas. Isto dá possibilidade de atuar em vários campos e ao mesmo tempo uma responsabilidade enorme no sentido de mostrar para a comunidade mas não impor o que se acha que é verdadeiro. No caso do Maciço do Morro da Cruz, na área central de Florianópolis, fomos convidados pelo Pe. Vilson Groh a prestar assessoria aos diversos comitês que o Fórum do Maciço tinha criado. Eles têm lá um comitê de segurança, um de cultura e educação e um de meio ambiente. Nós como Laboratório de Análise Ambiental trabalhamos junto com alunos estas questões (menos com a segurança, por uma questão de segurança nossa). Na questão de cultura e educação, por exemplo, o Luciano Henning fez um trabalho muito interessante no sentido de mapear os alunos das escolas que atendem as crianças do Morro da Cruz. E em meio ambiente trabalhamos muito com as encostas, para verificar áreas de risco, como também as áreas de proteção ambiental. Isto envolveu um bom número de professores do pós-gradução em Geografia, como o Joel Pellerin, a Dolores, o Luiz AntonioPaulino, a Margareth e o Luis Pimenta, a Ângela Beltrame e a Maria Lúcia Herrmann. Foram feitos duas teses, várias dissertações e vários TCCs. Então a questão da extensão universitária é complexa porque se vai revestido de uma autoridade científica, mas tem que se tomar cuidado para não impor, as pessoas é que tem que fazer as suas escolhas. Estou ainda orientando uma tese de doutorado sobre as ZEIS, Zonas Especiais de Interesse Social, no Maciço do Morro da Cruz.

Outra experiência interessante foi aquela derivada da catástrofe de 1995, que começou como extensão. Nós já estávamos trabalhando com pesquisa no Projeto Qualidade Ambiental do Sul de Santa Catarina, estudando diversos aspectos e especialmente as encostas, que sempre nos preocuparam. E no Natal de 1995 houve a tragédia 
Entrevista com o professor Luiz Fernando Scheibe

de grandes escorregamentos e corridas de detritos (debris flow), em que morreram 27 pessoas. As prefeituras de Jacinto Machado e de Timbé do Sul buscaram auxílio na universidade. A partir daí, vários professores e pós-graduandos da Geografia trabalharam na área buscando compreender os fenômenos e para mapear as zonas de risco. Realizamos projeto de educação ambiental, e apresentamos os mapas para as prefeituras. Os prefeitos, na verdade, queriam obras e não mapas, e quando falávamos da necessidade de respeitar as zonas em que existe o risco, alguns ouviram, outros não. De qualquer forma, o conhecimento acumulado naquela época foi muito importante depois, em 2008 nos escorregamentos do Vale do Itajaí, quando fomos chamados a colaborar, também como voluntários, na delimitação das áreas de risco.

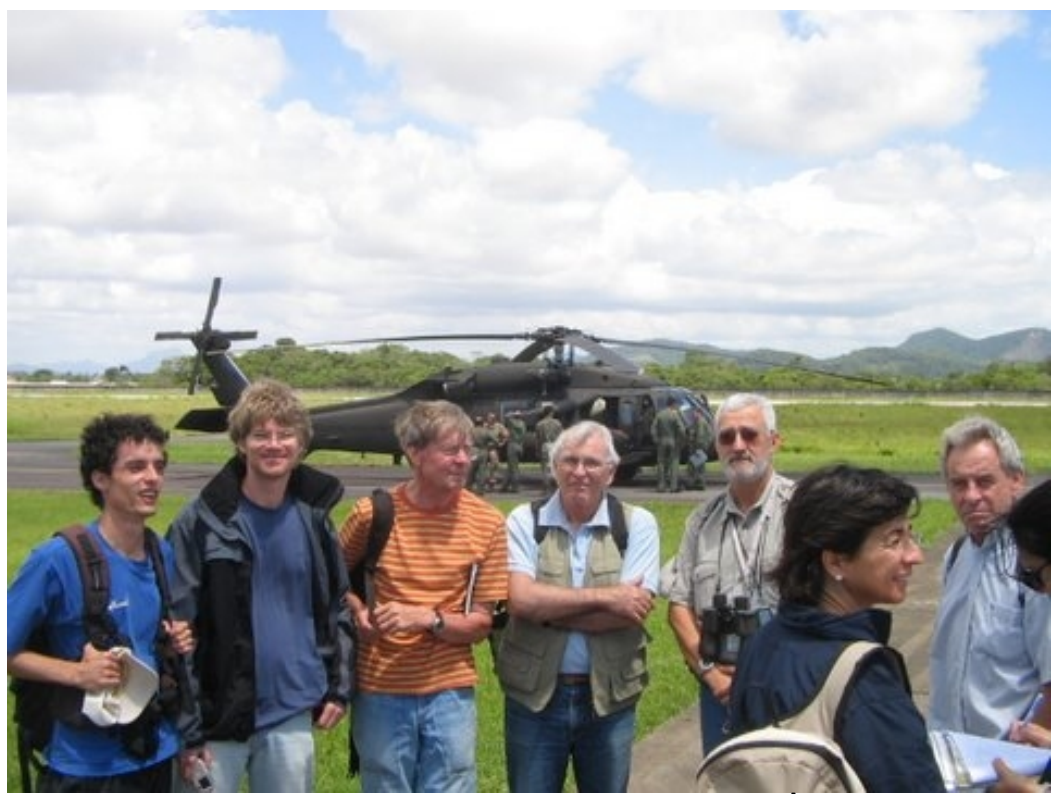

Foto: Harideva, Luciano, Joel, Scheibe, visitante, Ângela, Gré, em Navegantes, esperando para entrar no Black Hawk da Força nacional para acessar o Morro do Baú. 
Entrevista com o professor Luiz Fernando Scheibe

$\mathrm{O}$ conhecimento do sul do Estado também gerou inúmeras pesquisas, artigos, teses, dissertações e TCCs, hoje consolidados com a elaboração do Atlas Ambiental da Bacia do Araranguá (Ed. Cidade Futura, 2010), um trabalho monumental, co-organizado pelas Profas. Maria Dolores Buss e Sandra Maria de Arruda Furtado, que está sendo divulgado junto às escolas daquela bacia.

\section{BACIA HIDROGRÁFICA}

Com suas bordas altas e curvas e com seu

fundo chato, a bacia é o melhor objeto da

casa para recolher a água das goteiras durante os temporais...

Lá fora, a água da chuva vai procurar também

as partes mais baixas, encharcando o solo ou escorregando

para juntar-se com a dos terrenos vizinhos, formando

os córregos e riachos que, por sua vez, correm

todos para o rio principal, numa rede de drenagem

que acaba por ocupar todos os espaços dessa grande

bacia: a Bacia Hidrográfica.

Em seu caminho até o fundo do vale e depois até

a foz, a água pura da chuva vai carregando consigo

a poeira das estradas, as folhas secas das árvores, $o$

solo dos campos descobertos, o adubo e os agrotóxicos

recém aplicados, os esgotos das casas, das indústrias,

dos chiqueiros, os rejeitos da mineração.

O rio vai abrindo o seu caminho, criando peixes, purificando-se nas cachoeiras, abastecendo cidades, irrigando culturas e deixando nas planícies muitos dos materiais que não consegue mais carregar.

A história da bacia é a história de seu rio, dos seus vales e montanhas, campos e florestas. Mas é também a história de sua gente, que vive na bacia e que dela depende para viver, numa relação de solidariedade, em que da qualidade ambiental da bacia depende a qualidade de vida de seus habitantes.

Luiz Fernando Scheibe, In: Atlas Ambiental da Bacia do Rio Araranguá, 2010 
Entrevista com o professor Luiz Fernando Scheibe

Também ofertamos uma turma especial de mestrado em geografia para professores da UNESC, cujas reveladoras dissertações geraram o livro, organizado em parceria com as Profas. Sandra Maria de Arruda Furtado e Maria Dolores Buss, Geografias entrelaçadas: o rural e o urbano no sul de Santa Catarina (EdUFSC/EdUNESC, 2005).

GEOSUL - E agora, prestes a entrar na aposentadoria compulsória, a que ainda você pretende se dedicar? E Ao que, ao longo de todos estes anos, você acha que não deveria ter se dedicado tanto?

Prof. Scheibe - Tem uma crônica muito bonita que é atribuída a diversos autores que diz: "se eu nascesse de novo eu não correria tanto, daria mais atenção para as flores", etc. e tal. Confesso que não tem nada do que fiz que eu diria que não faria de novo. Não que eu tenha escolhido as coisas, como eu falei de Lages; você às vezes vai sendo levado pela vida. Nos últimos seis anos estou trabalhando em um projeto que se chama Rede Guarani/Serra Geral, que foi concebido na UNIPLAC e é coordenado pela profa. Maria de Fátima Wolkmer. Ela trouxe recursos para este projeto em Santa Catarina e eu tenho ajudado na parte técnica relativa às águas subterrâneas. É um projeto que envolve mais de 70 pesquisadores no estado, e a coordenação desta rede é muito complexa. Participam, da UFSC, os professores Carlos Henrique Lemos Soares, Arthur Nanni, Joel Pellérin, Luiz Antonio Paulino, Gerusa Maria Duarte, Luiz Carlos Pittol Martini, Edison Ramos Tomazolli, Juan Antonio Altamirano Flores, entre outros, no sentido de buscar o aproveitamento integrado e sustentável das águas subterrâneas, superficiais e da chuva. Apesar de em Santa Catarina sermos ricos em recursos hídricos, temos muitos problemas com poluição: no sul do estado o carvão, na região de Lages algumas papeleiras, na região oeste a suinocultura, e o problema dos esgotos nas nossas cidades. Tudo isso causa muitos problemas à água, mas se a gente tiver mais conhecimento e 
Entrevista com o professor Luiz Fernando Scheibe

respeito certamente podemos deixar para as próximas gerações um legado rico para o que é primordial à vida: a água.

GEOSUL - E hoje, como você vê o departamento de Geociências do Centro de Filosofia e Ciências Humanas,com dois novos cursos: Oceanografia e Geologia.

Prof. Scheibe - Quanto aos novos cursos do Departamento, apoiei mas não tive um envolvimento maior com a formação do de oceanografia, mas eu sempre quis o de geologia. Talvez não tivesse tido, antes, a coragem necessária para propô-lo. Acho que ele surge agora numa conjuntura extremamente favorável, de grande demanda nacional e com um apelo muito forte, a partir da tragédia de 2008 no vale do Itajaí, com a busca dos bombeiros e da defesa civil por geólogos, que nos fez mais uma vez trabalhar como voluntários. Da proposta de projetos de pesquisa sobre esses desastres naturais surgiu o apoio da Reitoria, do pré-sal o apoio da Petrobrás, a possibilidade de algumas contratações pelo Reuni, a presença de alguns novos professores, juntaram as condições favoráveis para criação do curso. Com a minha aposentadoria muito próxima, não terei condições de assumir aulas na graduação em geologia, mas tenho certeza de que teremos, todos, muito orgulho deste curso. E se é um pouco paradoxal o fato destes cursos estarem no Centro de Filosofia e Ciências Humanas, por outro lado dá a eles a possibilidade de um convívio com questões que em outras universidades passam ao largo, então eu sou contrário à saída destes cursos para outros centros, pois a interação entre os professores e entre os alunos de outros cursos do centro dará certamente a eles um matiz mais humanístico, ao mesmo tempo que representa também um saudável desafio para os cursos de graduação e pós-graduação em Geografia

GEOSUL - A palavra está aberta para que você faça algum comentário que gostaria.

Prof. Scheibe - Tenho a fazer um agradecimento a todos os colegas e alunos que eu tive, pois certamente foi este convívio e a aceitação que sempre vivenciei na universidade que me 
Entrevista com o professor Luiz Fernando Scheibe

possibilitaram uma vida profissional, que embora ache que não está completa, até aqui me faz sentir bastante realizado. Preciso agradecer também a toda a comunidade do $\mathrm{CFH}$ pela distinção como Pesquisador de Destaque em 2010, nos 50 anos da UFSC. Mas quero ressaltar que nunca trabalhei sozinho. No meu currículo a lista de pessoas com as quais trabalhei, escrevi é imensa, isto porque sempre contei com companheiros, colaboradores, alunos, amigos. Acho que aquele grupo que conseguimos montar no LAAm é vitorioso. Vale ainda recordar o Takeda que nos ensinou a todos, tanto de geologia, geografia e da própria vida. A figura do prof. Peluso também tem que ser lembrada: ele com seus 80 anos contribuindo ainda com o departamento. Gostaria de poder imitálo, assim como ao Bigarella, ao Carlos Augusto...

GEOSUL - Agradecemos mais uma vez.

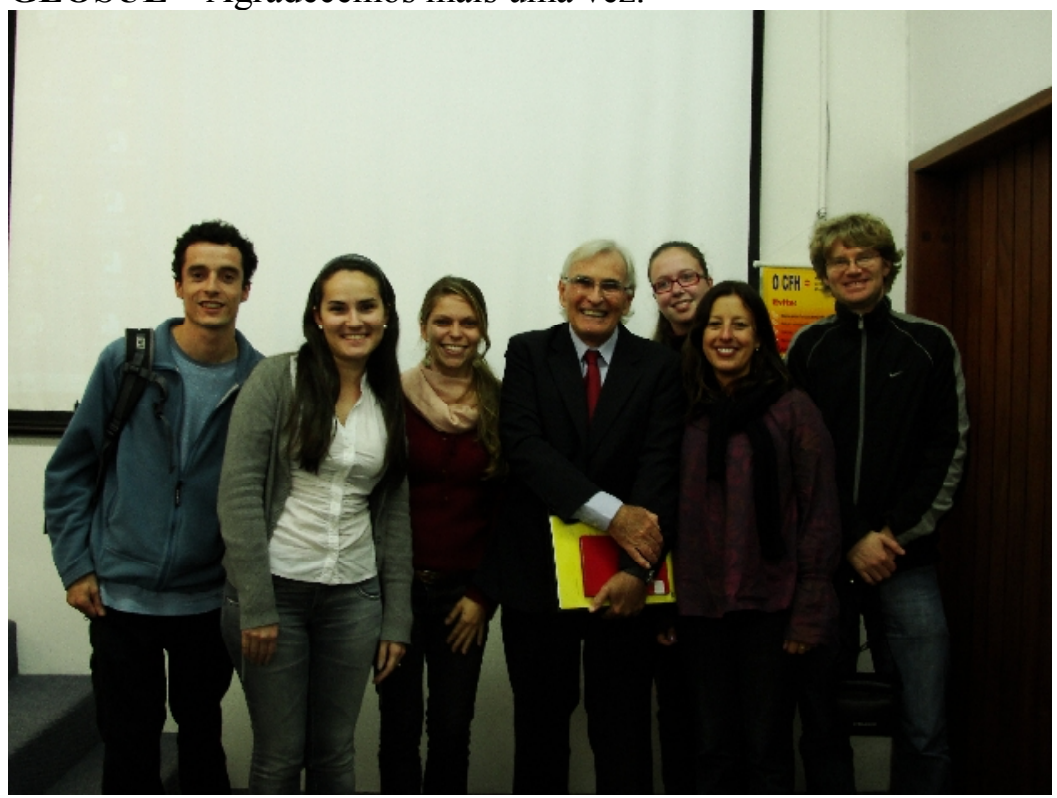

Foto: Prof. Scheibe com seus/suas orientandos/as do LAAm, na entrega do prêmio Pesquisador de Destaque, em 2010. 